\title{
Early estimates of seasonal influenza vaccine effectiveness in Europe: results from the I-MOVE multicentre case-control study, 2012/13
}

\author{
M Valenciano (m.valenciano@epiconcept.fr) ${ }^{1,2}$, E Kissling ${ }^{1,2}$, I-MOVE case-control study team ${ }^{3}$ \\ 1. EpiConcept, Paris, France \\ 2. These authors contributed equally to the work and share first authorship \\ 3. Members of the team are listed at the end of the article
}

Citation style for this article:

Valenciano M, Kissling E, I-MOVE case-control study team. Early estimates of seasonal influenza vaccine effectiveness in Europe: results from the

I-MOVE multicentre case-control study, 2012/13. Euro Surveill. 2013;18(7):pii=20400. Available online: http://www.eurosurveillance.org/ViewArticle. aspx?Articleld $=20400$

We conducted a test-negative case-control study based in five European sentinel surveillance networks. The early $2012 / 13$ adjusted influenza vaccine effectiveness was $78.2 \%$ (95\% Cl: 18.0 to 94.2$)$ against influenza $B, 62.1 \%(95 \% \mathrm{Cl}:-22.9$ to $88.3 \%)$ against $A\left(\mathrm{H}_{1}\right)$ pdmo9, 41.9 (95\% Cl: -67.1 to 79.8$)$ against $A\left(\mathrm{H}_{3} \mathrm{~N}_{2}\right)$ and $50.4 \%(95 \% \mathrm{Cl}:-20.7$ to 79.6$)$ against all influenza types in the target groups for vaccination. Efforts to improve influenza vaccines should continue to better protect those at risk of severe illness or complications.

\section{Background}

Since 2008/9, the Influenza Monitoring Vaccine Effectiveness (I-MOVE) network has estimated the effectiveness of seasonal influenza vaccine to prevent medically attended influenza-like illness (ILI) laboratory confirmed as influenza [1-7]. One of the components of I-MOVE is a multicentre case-control study based on practitioners participating in the European Influenza Surveillance Network (EISN) [8].

This season, six study sites are participating in the multicentre study: Germany, Ireland, Poland, Portugal, Romania and Spain.

Here we provide early season estimates of the 2012/13 influenza vaccine based on data collected from week 432012 to week 32013 . Poland is not included in the early season estimates as there were no vaccinated individuals among the patients recruited.

\section{Estimating influenza vaccine effectiveness}

The methods of the multicentre case-control study have been described previously [1-4,9].

Participating practitioners swabbed and interviewed all or a systematic sample of patients consulting for ILI. The common variables collected in all study sites were symptoms, date of onset and swabbing, 2012/13 seasonal vaccination status and date of vaccination, sex, age, presence of chronic conditions and number of hospitalisations for the chronic condition in the past 12 months. Four of the five study sites included a question on belonging to the target groups for vaccination. In Portugal, this information was gathered using information on age, chronic conditions, pregnancy, whether the patient was a health professional or carer and a household member or carer of an at-risk patient aged less than six months.

In the pooled analysis, we included patients with a nasopharyngeal swab taken less than eight days after symptom onset and meeting the European Union case definition for ILI: sudden onset of symptoms, at least one of four systemic symptoms (fever or feverishness, malaise, headache, myalgia) and at least one of three respiratory symptoms (cough, sore throat, shortness of breath) [10]. A case of confirmed influenza was an ILI patient who was swabbed and tested positive for influenza virus using real-time reverse-transcription polymerase chain reaction or culture. Controls were ILI patients who tested negative for any influenza virus.

We defined a person as vaccinated if he or she had received at least one dose of a 2012/13 seasonal influenza vaccine more than 14 days before ILI symptom onset. All the others were classified as unvaccinated.

For each study site we included ILI patients with symptom onset up to the end of week 32013 and more than 14 days after the start of national or regional influenza vaccination campaigns.

We conducted a complete case analysis excluding individuals with missing information on key confounders. We estimated the pooled seasonal influenza vaccine effectiveness (VE) as 1 minus the odds ratio (OR) expressed as a percentage, using a one-stage method with the study site as fixed effect in the model. 


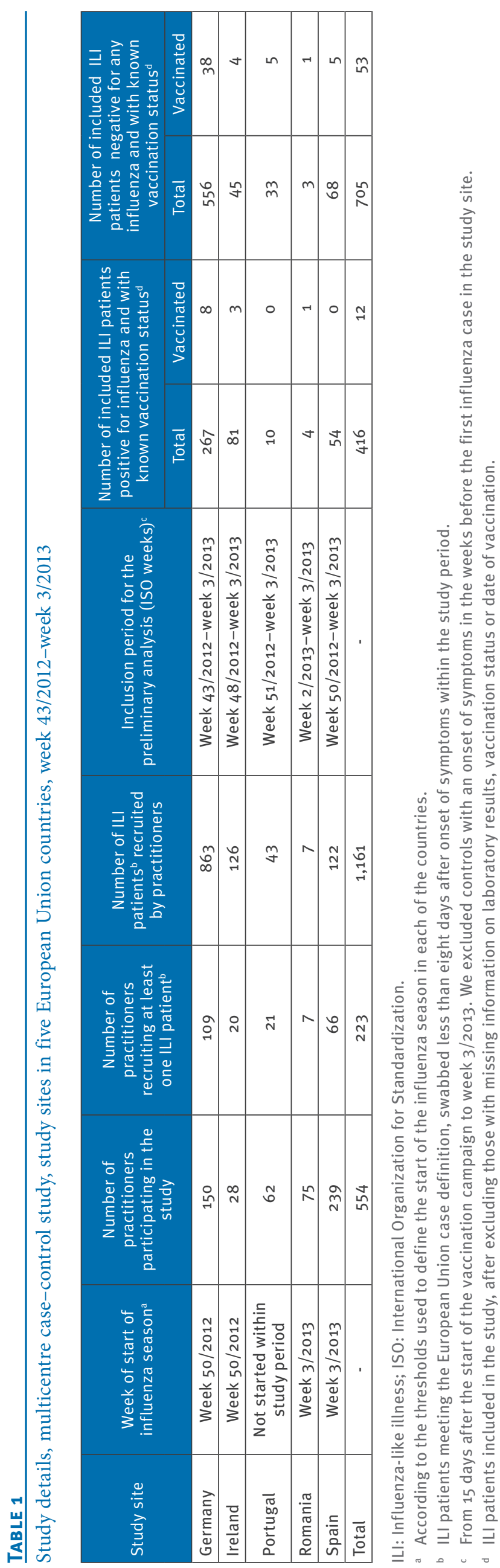

We used a logistic regression model to adjust for presence of at least one chronic disease, sex, age group and month of symptom onset.

We estimated VE against all laboratory-confirmed influenza, and individually against influenza $A\left(\mathrm{H}_{3} \mathrm{~N}_{2}\right)$, $A\left(H_{1} N_{1}\right) p d m o g$ and influenza $B$. For each study site, we excluded controls with symptom onset in the weeks before symptom onset of the first influenza type/ subtype case depending on the outcome used. We also estimated VE restricted to the target groups for vaccination.

\section{Early estimates of 2012/13 influenza vaccine effectiveness}

In the five countries, the influenza season, as defined by national thresholds, started at different times - in week 502012 in Germany and Ireland, week 32013 in Spain and Romania (Table 1). In week 3, the ILI incidence in Portugal was still below the threshold defining the start of the season. The first study site to recruit cases was Germany (in week 43 2012) and the last Romania (in week 2 2013).

Among 554 practitioners, 223 recruited at least one ILI patient (Table 1).

Of the 1,161 ILI patients enrolled, 271 tested positive for influenza A (23.3\%), 162 for influenza B (14.0\%) and one tested positive for both influenza $B$ and influenza $A\left(H_{1}\right)$ pdmog. Among the 269 influenza $A$ viruses that could be subtyped, $146(54.3 \%)$ were $A\left(\mathrm{H}_{1}\right)$ pdmog and $123(45.7 \%)$ were $A\left(\mathrm{H}_{3} \mathrm{~N}_{2}\right)$. Influenza $A$ virus was predominant in Germany, and influenza B in Ireland and Spain (Table 2).

The proportion of patients who were vaccinated was $2.9 \%(12 / 416)$ among cases and 7.5\% (53/705) among controls.

After excluding patients with missing information on $2012 / 13$ influenza vaccination $(n=40)$, age $(n=2)$, sex $(n=11)$, presence of chronic conditions $(n=62)$, we included 1,046 individuals (396 cases and 650 controls) in the complete case analysis (Figure). There were 12 vaccinated cases: five positive for influenza $A\left(H_{3} N_{2}\right)$, four for $A\left(H_{1}\right) p d m o g$ and three for $B$.

The adjusted VE was $62.2 \%$ (95\% Cl: 21.1 to 81.9 ) for influenza A and B combined, $78.2 \%(95 \% \mathrm{Cl}: 18.0$ to 94.2) for influenza B, $62.1 \%$ (95\% Cl: -22.9 to 88.3 ) for $\mathrm{A}\left(\mathrm{H}_{1}\right)$ pdmog and $41.9(95 \% \mathrm{Cl}:-67.1$ to 79.8$)$ for $\mathrm{A}\left(\mathrm{H}_{3} \mathrm{~N}_{2}\right)$ (Table 3). Among the target groups for vaccination, the $V E$ against influenza $A$ and $B$ combined was $50.4 \%$ ( $95 \% \mathrm{Cl}:-20.7$ to 79.6$)$.

\section{Discussion}

These early estimates suggest a moderate VE against all influenza viruses. By type and subtype, the highest VE was against influenza $B$ and the lowest against influenza $\mathrm{A}\left(\mathrm{H}_{3} \mathrm{~N}_{2}\right)$. 


\section{TABLE 2}

Details for influenza B ( $\mathrm{n}=163), A(H 3 N 2)(\mathrm{n}=123), A(H 1) p d m 09(\mathrm{n}=146)$ cases and controls ${ }^{\mathrm{a}}(\mathrm{n}=727)$ considered for mid2012/13 season trivalent influenza vaccine effectiveness analysis, study sites in five European Union countries, week 40/2012-week 3/2013 ( $\left.n=1,161^{\text {b,c }}\right)$

\begin{tabular}{|c|c|c|c|c|}
\hline Variables & $\begin{array}{l}\text { Number of test-negative } \\
\text { controls }{ }^{c} / \text { total } n(\%)\end{array}$ & 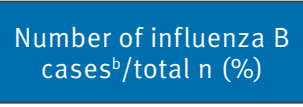 & $\begin{array}{c}\text { Number of influenza } \\
\mathrm{A}\left(\mathrm{H}_{3} \mathrm{~N}_{2}\right) \text { cases/total } \\
\mathrm{n}(\%)\end{array}$ & $\begin{array}{c}\text { Number of influenza } \\
\mathrm{A}\left(\mathrm{H}_{1}\right) \text { pdmog } \text { cases }^{\mathrm{b}} / \\
\text { total } \mathrm{n}(\%)\end{array}$ \\
\hline Median age (years) & 20 & 31 & 11 & 25.5 \\
\hline \multicolumn{5}{|l|}{ Age groups (years) } \\
\hline $0-4$ & $184 / 725(25.4)$ & $16 / 163(9.8)$ & $33 / 123(26.8)$ & $25 / 146(17.1)$ \\
\hline $5-14$ & $130 / 725(17.9)$ & $51 / 163(31.3)$ & $38 / 123(30.9)$ & $35 / 146(24.0)$ \\
\hline $15-59$ & $350 / 725(48.3)$ & $84 / 163(51.5)$ & $41 / 123(33.3)$ & $79 / 146(54.1)$ \\
\hline$\geq 60$ & $61 / 725(8.4)$ & $12 / 163(7.4)$ & $11 / 123(8.9)$ & $7 / 146(4.8)$ \\
\hline \multicolumn{5}{|l|}{ Sex } \\
\hline Female & $368 / 714(51.5)$ & $84 / 162(51.9)$ & $56 / 122(45.9)$ & $85 / 146(58.2)$ \\
\hline \multicolumn{5}{|c|}{ Days between symptom onset and swabbing } \\
\hline 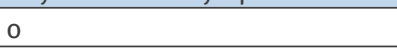 & $60 / 727(8.3)$ & $6 / 163(3.7)$ & $2 / 123(1.6)$ & $8 / 146(5.5)$ \\
\hline 1 & $294 / 727(40.4)$ & $34 / 163(20.9)$ & $52 / 123(42.3)$ & $55 / 146(37.7)$ \\
\hline 2 & $171 / 727(23.5)$ & $41 / 163(25.2)$ & $34 / 123(27.6)$ & $37 / 146(25.3)$ \\
\hline 3 & $112 / 727(15.4)$ & $43 / 163 / 26.4)$ & $17 / 123(13.8)$ & $23 / 146(15.8)$ \\
\hline $4-7$ & $90 / 727(12.4)$ & $39 / 163(23.9)$ & $18 / 123(14.6)$ & $23 / 146(15.8)$ \\
\hline Seasonal vaccination ${ }^{\mathrm{d}} 2012 / 13$ & $53 / 705(7.5)$ & $3 / 161(1.9)$ & $5 / 117(4 \cdot 3)$ & $4 / 136(2.9)$ \\
\hline At least one chronic condition & $143 / 676(21.2)$ & $29 / 161(18.0)$ & $14 / 114(12.3)$ & $18 / 134(13.4)$ \\
\hline $\begin{array}{l}\text { At least one hospitalisation } \\
\text { in the previous } 12 \text { months for } \\
\text { chronic conditions }\end{array}$ & $11 / 584(1.9)$ & $2 / 152(1.3)$ & $2 / 103(1.9)$ & $0 / 122(0.0)$ \\
\hline $\begin{array}{l}\text { Belongs to target groups for } \\
\text { vaccination }\end{array}$ & $175 / 711(24.6)$ & $35 / 163(21.5)$ & $22 / 117(18.8)$ & $23 / 143(16.1)$ \\
\hline \multicolumn{5}{|l|}{ Study sites } \\
\hline Germany & $578 / 727(79.5)$ & $51 / 163(31.3)$ & $112 / 123(91.1)$ & $122 / 146(83.6)$ \\
\hline Ireland & $45 / 727(6.2)$ & $66 / 163(40.5)$ & $9 / 123(7.3)$ & $5 / 146(3.4)$ \\
\hline Portugal & $33 / 727(4.5)$ & $4 / 163(2.5)$ & $0 / 123(0.0)$ & $6 / 146(4.1)$ \\
\hline Romania & $3 / 727(0.4)$ & $2 / 163(1.2)$ & $0 / 123(0.0)$ & $2 / 146(1.4)$ \\
\hline Spain & $68 / 727(9.4)$ & $40 / 163(24.5)$ & $2 / 123(1.6)$ & $11 / 146(7.5)$ \\
\hline
\end{tabular}

a Controls used to compare with all influenza cases.

b One influenza case positive for influenza B and for influenza $A\left(\mathrm{H}_{1}\right)$ pdmog was included in both analyses.

c The virus from three influenza A cases could not be subtyped: these cases are not included in the descriptive analysis.

d Vaccination more than 14 days before onset of influenza-like illness symptoms.

\section{TABLE 3}

Pooled crude and adjusted 2012/13 seasonal vaccine effectiveness against laboratory confirmed influenza by influenza type/ suptype, overall and among target groups for vaccination. Multicentre case-control study in five European Union study sites, week 43 (2012)-week 3 (2013), influenza season 2012/13

\begin{tabular}{|c|c|c|c|c|c|}
\hline Influenza type/subtype & $\begin{array}{c}\text { Crude vs adjusted } \\
\text { model }\end{array}$ & $\begin{array}{l}\text { Cases and controls } \\
(\mathrm{n} / \mathrm{n})\end{array}$ & $\begin{array}{l}\text { Vaccinated cases and } \\
\text { controls }(n / n)\end{array}$ & $\begin{array}{c}\text { Vaccine effectiveness } \\
(\%)\end{array}$ & $\begin{array}{l}95 \% \text { confidence } \\
\text { intervals }\end{array}$ \\
\hline \multicolumn{6}{|l|}{ All population } \\
\hline \multirow{2}{*}{$A$ and $B$} & Crude $^{a}$ & $396 / 650$ & $12 / 48$ & 62.8 & 27.3 to 80.9 \\
\hline & Adjusted $^{b}$ & $396 / 650$ & $12 / 48$ & 62.2 & 21.1 to 81.9 \\
\hline \multirow{2}{*}{$\mathrm{A}\left(\mathrm{H}_{1}\right)$ pdmog } & Crude $^{\mathrm{a}}$ & $125 / 477$ & $4 / 37$ & 66.1 & -2.7 to 88.8 \\
\hline & Adjusted $^{c}$ & $125 / 477$ & $4 / 37$ & 62.1 & -22.9 to 88.3 \\
\hline \multirow{2}{*}{$\mathrm{A}\left(\mathrm{H}_{3} \mathrm{~N}_{2}\right)$} & Crude $^{a}$ & $111 / 577$ & $5 / 39$ & 34.7 & -70.1 to 74.9 \\
\hline & Adjusted $^{b}$ & $111 / 577$ & $5 / 39$ & 41.9 & -67.1 to 79.8 \\
\hline \multirow{2}{*}{ B } & Crude $^{\mathrm{a}}$ & $158 / 523$ & $3 / 41$ & 79.8 & 29.2 to 94.2 \\
\hline & Adjusted $^{b}$ & $158 / 523$ & $3 / 41$ & 78.2 & 18.0 to 94.2 \\
\hline \multicolumn{6}{|l|}{ Target population } \\
\hline \multirow[b]{2}{*}{$A$ and $B$} & Crude $^{a}$ & $73 / 157$ & $9 / 32$ & 46.5 & -23.0 to 76.8 \\
\hline & Adjusted $^{d}$ & $73 / 154$ & $9 / 32$ & 50.4 & -20.7 to 79.6 \\
\hline
\end{tabular}

a Study site included in the model as fixed effect.

b Model adjusted for presence of at least one chronic disease, sex, 10-year age group and month of symptom onset.

Model adjusted for presence of at least one chronic disease, sex, 10 -year age group until age 60 , where age is coded as $\geq 60$ years and month of symptom onset.

d Model adjusted for presence of at least one chronic disease, sex, age group $(0-14 ; 15-59$ and $\geq 60$ years) and month of symptom onset. Three records were excluded for October. 
During the study period, as of week 3-2013, two of the participating countries reported a low ILI/ARI activity (Portugal, Romania) and three medium activity (Germany, Ireland, Spain) [11].The sample size varied by study site. As most patients $(863 / 1,161,74.3 \%)$ were enrolled in Germany, the pooled estimates are highly influenced by the German data. When restricting the analysis to Ireland, Portugal, Romania and Spain $(n=296$, four vaccinated cases), the adjusted point VE against all influenza was higher $(73.5 \% ; 95 \% \mathrm{Cl}: 8.7$ to 92.3) than the adjusted point VE including the five study sites.

As in 2011/12, the results suggests a low-to-moderate VE for influenza $\mathrm{A}\left(\mathrm{H}_{3} \mathrm{~N}_{2}\right)$ [9]. Our point estimate is lower than that reported by Canada [12] and the United States [13], countries with a predominance of this subtype in the early phase of the 2012/13 season. Most of the influenza $A\left(\mathrm{H}_{3} \mathrm{~N}_{2}\right)$ cases included in our study were German patients. In Germany, most of

\section{FIGURE}

Flowchart of data exclusion for pooled analysis, I-MOVE multicentre case-control study, influenza season 2012/13

Number of records received for pooled analysis:

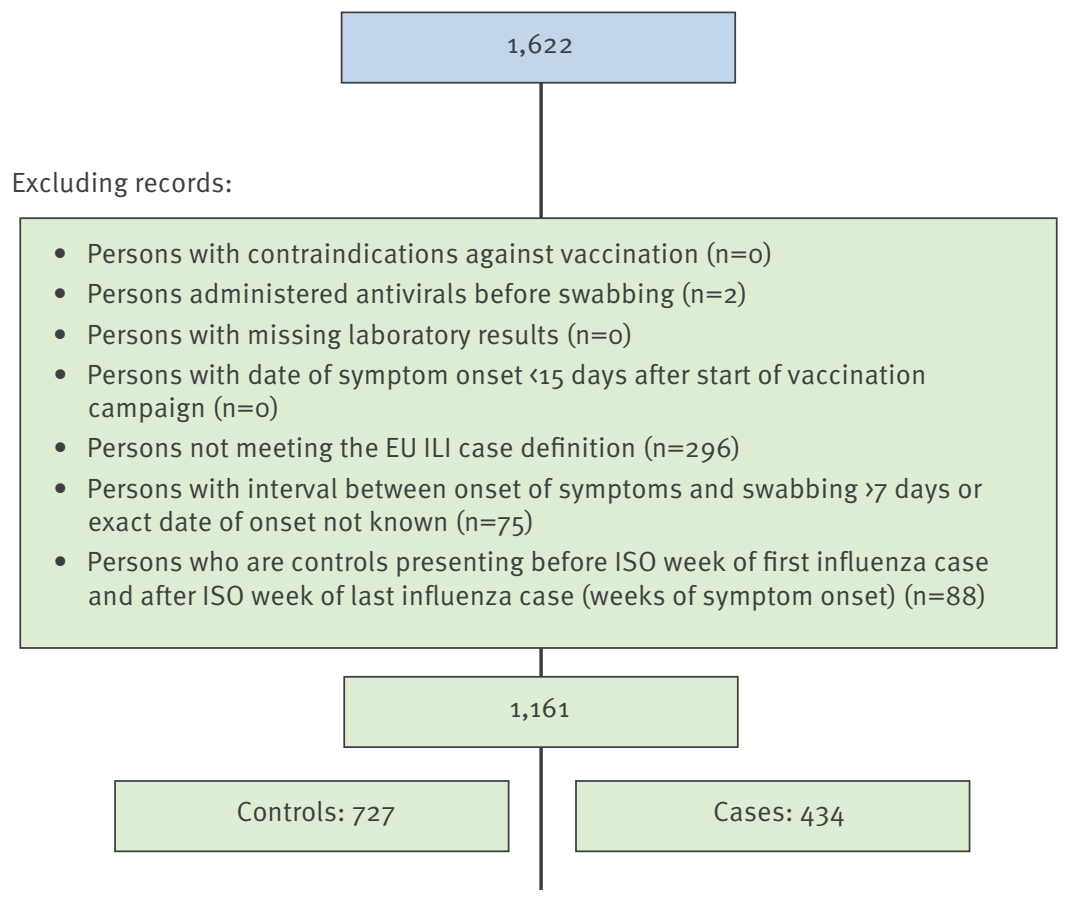

Excluding records with missing 2012/13 influenza vaccination status $(n=40)$ :

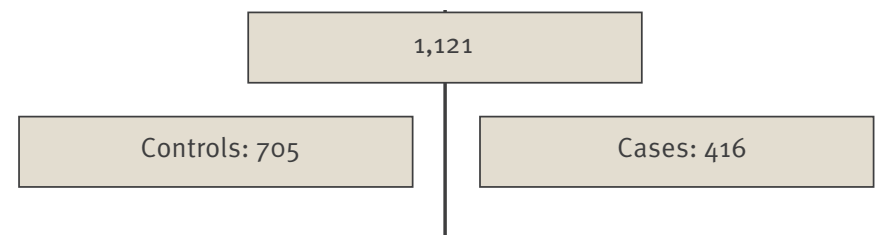

Excluding records with missing data from covariates for complete case analysis:
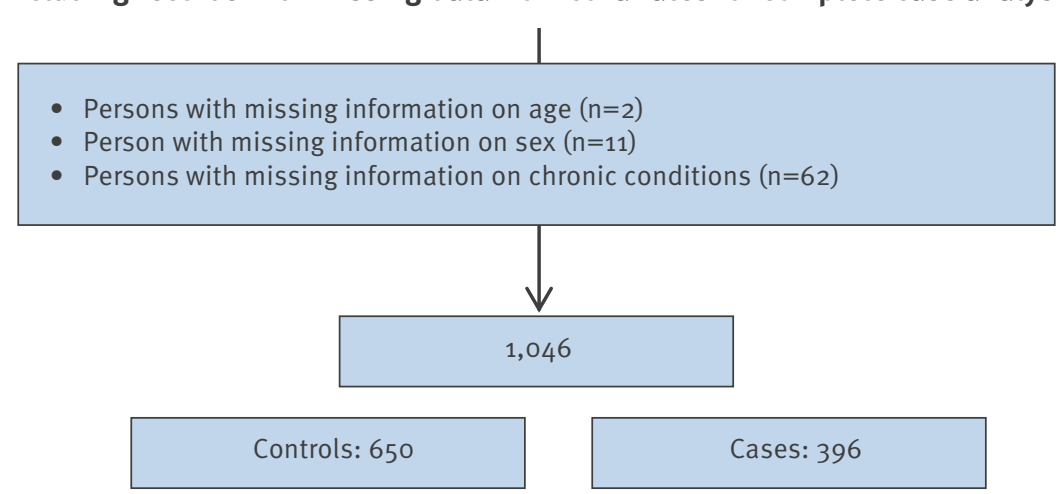
the 103 influenza $\mathrm{A}\left(\mathrm{H}_{3} \mathrm{~N}_{2}\right)$ viruses characterised at the national reference centre for influenza were similar to the $\mathrm{A} /$ Victoria/361/2011 $\left(\mathrm{H}_{3} \mathrm{~N}_{2}\right)$ vaccine virus for the 2012/13 season [14]. This similarity was also reported by the Community Network of Reference Laboratories for Human Influenza in Europe (CNRL) [15]. This discrepancy between the apparently well-matched vaccine strain/circulating strains and low VE has also been noted this season in Canada [12].

Our 2013 early point VE estimates for influenza B are similar to estimates from the United States [13] and higher than those reported in the United Kingdom [16]. All the influenza B virus isolates genetically characterised from influenza cases enrolled in the Irish (three isolates), Portuguese (three isolates) and Spanish (four isolates) study sites were B/Yamagata, the lineage included in the 2012/13 vaccine. Data from the German national reference centre for influenza indicated that among 75 influenza B strains characterised, 68 were Yamagata and 7 Victoria.

The sample size did not allow VE estimation by type and subtype among the target population for vaccination. The low VE against all influenza types in this population is similar to the estimates the I-MOVE multicentre case-control study provided last season against influenza $A\left(\mathrm{H}_{3}\right)[3]$.

This season, in which different influenza viruses are co-circulating in Europe, the I-MOVE multicentre casecontrol study provided early adjusted VE estimates for influenza $B, A\left(\mathrm{H}_{3} \mathrm{~N}_{2}\right)$ and $A\left(\mathrm{H}_{1} \mathrm{~N}_{1}\right)$ pdmog viruses. However, due to small sample size, the precision around these estimates is low and should be taken into account when interpreting these preliminary results.

The results underscore the importance of providing early VE estimates against virus subtype regardless of the reported relatedness between circulating viruses and administered vaccines. The early VE estimates could be useful when defining the recommendations for next season's vaccine composition.

In conclusion, our early season estimates suggest that the $2012 / 13$ influenza vaccine is effective in preventing medically attended laboratory-confirmed influenza, with a higher VE against influenza $B$ than against influenza A subtypes. The lower VE among the target groups and against influenza $A\left(\mathrm{H}_{3} \mathrm{~N}_{2}\right)$ underlines that efforts to improve the influenza vaccine should continue in order to better protect those at risk of severe illness or complications.

Members of the I-MOVE case-control study team

EpiConcept, Paris, France: Esther Kissling, Alain Moren, Marta Valenciano; Germany: Annicka Reuss, Udo Buchholz, Silke Buda, Unit for Respiratory Infections, Department for Infectious Disease Epidemiology, Robert Koch Institute; Ireland: Justyna Rogalska, European Programme for Intervention Epidemiology Training (EPIET), Stockholm,
Sweden, and Health Protection Surveillance Centre; Joan O'Donnell, Lisa Domegan, Darina O'Flanagan, Health Protection Surveillance Centre; Claire Collins, Michael Joyce, Irish College of General Practitioners; Suzie Coughlan, Joanne Moran, National Virus Reference Laboratory; Portugal: Baltazar Nunes, Ausenda Machado, Ines Batista, Departamento de Epidemiologia, Instituto Nacional de Saúde Dr. Ricardo Jorge; Raquel Guiomar, Pedro Pechirra, Paula Cristovão, Patricia Conde, Departamento de Doenças Infeciosas, Instituto Nacional de Saúde Dr. Ricardo Jorge; Isabel Falcão; Unidade de Emergencias em Saúde Pública, Direção Geral da Saúde; Romania: Viorel Alexandrescu, Emilia Lupulescu, Alina Ivanciuc, Gheorghe Necula, Cantacuzino Institute, National Institute of Research - Development for Microbiology and Immunology; Daniela Pitigoi Cantacuzino Institute, National Institute of Research - Development for Microbiology and Immunology and Universitatea de Medicina si Farmacie Carol Davila; Spain: Amparo Larrauri, Silvia Jiménez-Jorge, Salvador de Mateo, National Centre of Epidemiology, Institute of Health Carlos III; Francisco Pozo, Inmaculada Casas National Centre for Microbiology, National Influenza Reference Laboratory, WHO-National Influenza Centre, Institute of Health Carlos III.

\section{Acknowledgements}

We are grateful to all patients, practitioners and epidemiologists from the five study sites who actively participated in the study.

Germany: Brunhilde Schweiger, National Reference Centre for Influenza, Robert Koch Institute; Michael Herzhoff, Unit for Data Management, Department for Infectious Disease Epidemiology, Robert Koch Institute; Poland: Iwona Paradowska-Stankiewicz, Malgosia Gluchowska, Lidia Brydak, AgnieszkaWozniak-Kosek; Portugal: Carlos Matias Dias, José Marinho Falcão (retired), Department of Epidemiology, Instituto Nacional de Saúde Dr Ricardo Jorge, Lisbon; Associação Portuguesa de Médicos de Clínica Geral [Portuguese association of general practitioners]; Romania: Adriana Pistol, Rodica Popescu, National Centre for Surveillance and Control of Communicable Diseases,; epidemiologists from sentinel Public Health Directorates Camelia Truica, Elena Duca, Suzan Ibram, Dan Decebal, Mariana Ioan, Carmen Sima, Georgeta Marga, Viorica Mihalascu, Carmen Scintei, Cornelia Anghel; Spain: Jesús Castilla and Manuel García Cenoz, Instituto de Salud Pública de Navarra, Navarra, CIBERESP; Jone M. Altzibar (Subdirección de Salud Pública de Guipuzkoa, País Vasco. CIBERESP), Fernando González Carril (Servicio de Salud Pública, Departamento de Salud, Gobierno del País Vasco); Virtudes Gallardo and Esteban Pérez, Servicio de Epidemiología y Salud Laboral. Secretaría General de Salud Pública y Participación. Consejería de Salud de Andalucía; Jaume Giménez, Juana M. Vanrell, Servicio de Epidemiología, Dirección General de Salut Pública, Baleares, Palma de Mallorca, CIBERESP; Carmen Quiñones and Eva Martinez, Servicio de Epidemiología, Subdirección de Salud Pública de La Rioja; Daniel Castrillejo, Servicio de Epidemiología. Dirección General de Sanidad y Consumo, Consejería de Bienestar Social y Sanidad, Ciudad Autónoma de Melilla;Tomás Vega, Milagros Ortiz, Dirección General de Salud Pública e Investigación, Desarrollo e Innovación,Consejería de Sanidad de Castilla y León; Julián M. Ramos, Maria C. Serrano, Dirección General de Salud Pública, Servicio Extremeño de Salud, Junta de Extremadura.

\section{Funding}

The I-MOVE multicentre case-control study is funded by study sites (Germany, Ireland, Portugal, Romania, Spain) and EpiConcept (coordination, pooled analysis). World Health Organization Regional Office for Europe contributes to the funding of the study in Romania. 


\section{Conflict of interest}

None declared. EpiConcept analyses pooled data of a hospital-network multicentre case-control (HNMCC) study measuring influenza VE. The HNMCC analysis is co-funded by Pasteur, Sanofi Pasteur MSD, GlaxoSmithKline and EpiConcept.

\section{Authors' contributions}

Marta Valenciano led the writing of the rapid communication. Esther Kissling undertook the statistical analysis on which the rapid communication is based. All authors participated in the interpretation of the study and contributed to the revision of the draft manuscript and approving the final version. Alain Moren, Marta Valenciano, Esther Kissling were involved in the original methodological design of the multicentre case-control study. Amparo Larrauri, Silvia Jiménez-Jorge, Joan O’Donnell, Emilia Lupulescu, Daniela Pitigoi, Baltazar Nunes, Ausenda Machado, Annicka Reuss, Udo Buchholz have had a role in modification of this design over the years.

Germany: Annicka Reuss, Udo Buchholz and Silke Buda are responsible for validation of data and interpretation of results. Ireland: Justyna Rogalska was involved in the collection and collation of the data. Joan O'Donnell was involved in the original methodology and final review of the paper. She was also coordinating the project in Ireland. Lisa Domegan was involved in collection, collation and analysis of clinical and virological data from all sentinel GPs. Darina O'Flanagan was involved in the original initiation of the ILI surveillance system and approved the final communication. Claire Collins was involved in the original study design. In this round, she contributed to the preparation of the ethical submission and coordinated the invitation letter to participating GPs and the GP payments. Michael Joyce was involved in the collection and collation of the data. Joanne Moran and Suzie Coughlan - Extraction of sentinel influenza I-MOVE data from the National Virus Reference Laboratory information system (NVRL LIMs) on a weekly basis for distribution to the Health Protection Surveillance Centre (HPSC). Portugal: Baltazar Nunes, Ausenda Machado, Raquel Guiomar and Pedro Pechirra were responsible for the study design in Portugal study site. Ausenda Machado, Inês Batista, were responsible for the field work, study monitoring, data validations and preparation. Pedro Pechirra, Paula Cristovão and Patricia Conde were responsible for the laboratory analysis: virus sub-typing, genotyping and laboratory data validation. Romania: Daniela Pitigoi, Emilia Lupulescu, Viorel Alexandrescu coordinated the Romanian study. Daniela Pitigoi and Emilia Lupulescu were responsible for the study design in Romania study site. Daniela Pitigoi, Emilia Lupulescu, Gheorghe Necula collected data. Daniela Pitigoi, Alina Ivanciuc enrolled patients. Spain: Amparo Larrauri and Silvia Jiménez-Jorge participated in the coordination of the Spanish study and the national database. Salvador de Mateo was involved in the interpretation and analysis of the Spanish study. Francisco Pozo and Inmaculada Casas were involved in genetic characterisation of influenza virus from the Spanish Influenza Surveillance System.

\section{References}

1. Kissling $E$, Valenciano $M$, Cohen IM, Oroszi B, Barret AS, Rizzo C, et al. I-MOVE multi-centre case control study 201011: overall and stratified estimates of influenza vaccine effectiveness in Europe. PLoS One. 2011;6(11):e27622.

2. Kissling E, Valenciano M; I-MOVE case-control studies team. Early estimates of seasonal influenza vaccine effectiveness in Europe, 2010/11: I-MOVE, a multicentre case-control study. Euro Surveill. 2011;16(11):pii=19818. Available from: http:// www.eurosurveillance.org/ViewArticle.aspx?Articleld $=19818$

3. Kissling E, Valenciano M; I-MOVE Case-Control Studies Team. Early estimates of seasonal influenza vaccine effectiveness in Europe among target groups for vaccination: results from the I-MOVE multicentre case-control study, 2011/12. Euro Surveill. 2012;17(15):pii=20146. Available from: http://www. eurosurveillance.org/ViewArticle.aspx?Articleld =20146

4. Valenciano $M$, Kissling $E$, Cohen IM, Oroszi B, Barret AS, Rizzo $C$, et al. Estimates of pandemic influenza vaccine effectiveness in Europe, 2009-2010: results of Influenza Monitoring Vaccine Effectiveness in Europe (I-MOVE) multicentre case-control study. PLoS Med. 2011;8(1):e1000388.

5. Valenciano M, Ciancio B, I-MOVE study team. I-MOVE: a European network to measure the effectiveness of influenza vaccines. Euro Surveill. 2012;17(39):pii=20281. Available from: http://www.eurosurveillance.org/ViewArticle. aspx?Articleld $=20281$

6. Castilla J, Morán J, Martínez-Artola V, Fernández-Alonso M, Guevara M, Cenoz MG, et al. Effectiveness of the monovalent influenza $A\left(\mathrm{H}_{1} \mathrm{~N}_{1}\right)_{2009}$ vaccine in Navarre, Spain, 2009-2010: cohort and case control study. Vaccine. 2011;29(35):591924. http://dx.doi.org/10.1016/j.vaccine.2011.06.063 PMid:21723358

7. Pebody R, Hardelid P, Fleming D, McMenamin J, Andrews N, Robertson C, et al. Effectiveness of seasonal 2010/11 and pandemic influenza $A\left(\mathrm{H}_{1} \mathrm{~N}_{1}\right) 2009$ vaccines in preventing influenza infection in the United Kingdom: mid-season analysis 2010/11. Euro Surveill. 2011;16(6): pii=19791. Available from: http://www.eurosurveillance.org/ViewArticle. aspx?Articleld $=19791$

8. European Centre for Disease Prevention and Control (ECDC). European Influenza Surveillance Network (EISN). Stockholm: ECDC. [Accessed 5 Feb 2013]. Available from: http://www.ecdc. europa.eu/en/activities/surveillance/eisn/pages/index.aspx

9. Kissling $E$, Valenciano $M$, Larrauri A, Oroszi B, Cohen I.M, Nunes $B$, et al. Low and decreasing vaccine effectiveness against influenza $A\left(\mathrm{H}_{3}\right)$ in 2011/12 among vaccination target groups in Europe: results from the I-MOVE multicentre case-control study. Euro Surveill. 2013;18(5):pii=20390. Available from: http://www.eurosurveillance.org/ViewArticle. aspx?Articleld $=20390$

10. European Commission. Commission Decision of 30 April 2009 amending Decision 2002/253/EC laying down case definitions for reporting communicable diseases to the Community network under Decision No 2119/98/EC of the European Parliament and of the Council (2009/363/EC). Official Journal of the European Union. Luxembourg: Publications Office of the European Union. 1.5.2009 L 110. Available from: http://eur-lex. europa.eu/LexUriServ/LexUriServ.do?uri=0J:L:2009:110:0058: 0059: EN:PDF

11. European Centre for Disease Prevention and Control (ECDC). Weekly influenza surveillance overview, 25 January 2013. Main surveillance developments in week 3/2013 (14-20 January 2013). Stockholm: ECDC; 2013. Available from: http://www. ecdc.europa.eu/en/publications/Publications/130125_SUR_ Weekly_Influenza_Surveillance_Overview.pdf

12. Skowronski DM, Januja NZ, De Serres G, Dickinson JA, Winter A-L, Mahmud SM, et al. Interim estimates of influenza vaccine effectiveness in 2012/13 from Canada's sentinel surveillance network, January 2013. Euro Surveill. 2013;18(5):pii=20394. Available from: http://www.eurosurveillance.org/ViewArticle. aspx?Articleld $=20394$

13. Centers for Diseases Control and Prevention (CDC). Early estimates of seasonal influenza vaccine effectiveness United States, January 2013. MMWR Morb Mortal Wkly Rep. 2013;62(02):32-5. Available from: http://www.cdc.gov/mmwr/ preview $/ \mathrm{mmwrhtml} / \mathrm{mm6202a4.htm?s} \mathrm{cid=mm6202a4} \mathrm{w}$

14. Buda S, Schweiger B, Buchholz U, Köpke K, Luchtenberg $\mathrm{M}$, Prahm K, et al. Kalenderwoche 4 (19.01. bis 25.01.2013). Influenza-Wochenbericht. [Week 4 (19.01 to 25.01.20130. Influenza weekly report]. Berlin: Robert Koch Institute; 2013. Available from: http://influenza.rki.de/ Wochenberichte/2012_2013/2013-04.pdf

15. European Centre for Disease Prevention and Control (ECDC). Influenza virus characterisation. Summary Europe, December 2012. Stockholm: ECDC; 2013. Available from: http://ecdc. europa.eu/en/publications/Publications/influenza-viruscharacterisation-CNRL-dec-2012.pdf

16. McMenamin J, Andrews N, Robertson C, Fleming DM, Durnall $\mathrm{H}$, Von Wissmann B, et al. Effectiveness of seasonal 2012/13 vaccine in preventing laboratory-confirmed influenza infection in primary care in the United Kingdom: mid-season analysis 2012/13. Euro Surveill. 2013;18(5): $\mathrm{pii}=20393$. Available from: http://www.eurosurveillance.org/ViewArticle. aspx?Articleld $=20393$ 